\title{
STREET, B. V. (ORG.) LITERACY AND DEVELOPMENT. ETHNOGRAPHIC PERSPECTIVES. LONDRES E NOVA YORK: ROUTLEDGE, 2001, 228 PÁGS.
}

\section{Resenhado por: Décio Bessa}

Literacy and development é uma ótima contribuição para os estudos etnográficos do letramento. Nas últimas três décadas os estudos nessa área têm se ampliado consideravelmente e é preciso registrar o que tem sido chamado de Novos Estudos do Letramento (New Literacy Studies), pois suas produções têm sido muito valorizadas. Podem ser citados, entre outros, os trabalhos de D. Barton e M. Hamilton (1998), D. Barton, M. Hamilton e R. IvaniÖ(1999), R. IvaniÖ(1997), e B. Street (1995), o organizador desta obra, na qual apresenta uma série de estudos realizados na Ásia, na África e na América Latina. Considerando que o letramento cumpre um papel relevante no contexto mundial de desenvolvimento, faz-se necessário então, compreender as ideologias nas teorias e práticas do discurso da "Educação para Todos", bem como as construções identitárias envolvidas. As perspectivas, ações e resultados vão sendo explicados nesse processo.

$\mathrm{Na}$ Introdução, Street busca clarificar os pressupostos, objetivos e as principais terminologias nos atuais estudos do letramento. Ele chama a atenção também para a influência das "novas ordens" (do trabalho, da comunicação e da epistemologia) nas questões de letramento que estão imbricadas no atual contexto de desenvolvimento. O autor faz uma discussão sobre eventos e práticas de letramento, mas seu texto publicado na obra de Martin-Jones e Jones (orgs., 2000) discute mais detalhadamente esses tópicos. Street, além de responder as críticas, o que colabora na compreensão dos estudos atuais e suas perspectivas, afirma que boas práticas educacionais dependem de "ouvir, não somente entregar" (p.14), ou seja, é preciso considerar de maneira mais ampla o que os aprendizes trazem consigo.

São apresentados, em seguida, dez capítulos divididos em duas partes, ambas com introdução de B. Street, que procurou contextualizá-las. A primeira, "Literacy and development: ethnographic perspectives on schooling and adult education" contém pesquisas realizadas principalmente na Índia e na África, relacionadas a intervenções educacionais em nível escolar ou em programas para adultos, observando as práticas de letramento locais como 
práticas sociais. O Capítulo 1, de C. Dyer e A. Choksi, intitulado "Literacy, schooling and development: views of Rabari nomads, India", discorre sobre uma pesquisa etnográfica de dois anos e meio entre os Rabaris de Kachchh, um grupo não-sedentário do estado de Gujaraty no oeste da Índia. Eles têm uma ocupação pastoril e cuidam principalmente de camelos e ovelhas. Migram cerca de nove meses durante o ano em busca de pastagem e água para os animais. Porém, as mudanças da sociedade moderna têm dificultado esse modo de vida. O interesse deles pelo letramento é influenciado pelo 'desenvolvimento' que os marginaliza social, econômica e politicamente. Foram pesquisados eventos e práticas de letramento, bem como uma tentativa de modelo itinerante de ensino. A pesquisa etnográfica contribuiu para perceber as concepções de conhecimento e identidade que influenciavam a compreensão de educação dos habitantes locais, para quem o letramento está amplamente associado a status social e poder; não ter educação, para eles, é a principal razão de serem e permanecerem 'retrógrados'. O sentido do letramento que eles possuem é muito amplo e se reflete na posição social em que eles se enxergam no mundo moderno. Não obstante as pesquisadoras terem experimentado um ensino itinerante com os Rabaris e terem obtido resultados positivos, ficou demonstrada a concepção deles de que o problema de sobrevivência do grupo dentro do sistema apenas seria resolvido com o processo de escolarização formal, no qual a criança não aprende só a ler e escrever, mas também a falar usar a linguagem e o comportamento do poder, o que acontece dentro de uma perspectiva sedentária. Só assim, acreditavam, teriam acesso aos capitais necessários (Bourdieu e Passeron, 1977). Um enorme problema é que as escolas que freqüientariam provavelmente reproduziriam as desigualdades sociais em vez de desafiá-las. A realidade dos Rabaris percebida pelas autoras demonstra, segundo elas, "que a existência de diferentes ideologias de letramento... precisam urgentemente ter reconhecimento e ação subseqüente" (p. 38). Dessa forma, seriam ligadas as concepções de letramento com ações apropriadas por meio dos programas de letramento.

No Capítulo 2, “' 'Literacy - your key to a better future?' Literacy reconciliation and development in the National Literacy Programme in Namibia”, assinado por U. Papen, são discutidos significados e usos do letramento no Programa Nacional de Letramento na Namíbia (PNLN), que foi iniciado pelo governo depois de o país ficar independente da África do Sul em 1990. O programa tem sido implementado em todas as regiões desde 1992. Ele é dividido em estágios: o primeiro e o segundo consistem em dois anos de leitura e escrita na linguagem local; o terceiro e o quarto, em um ou dois anos de letramento em inglês; do quinto ao sétimo, em três anos de curso básico (em 
inglês). A pesquisa é baseada na combinação de uma etnografia das práticas de letramento com uma análise política do PNLN. A autora descreve os usos e significados do letramento em diferentes contextos sociais e em cenários institucionais do PNLN, por exemplo: em salas, sessões de treinamento para professores de letramento e no vasto contexto que informa as decisões e escolhas particulares do programa. Nesse capítulo, a autora se mostra particularmente interessada nas amplas políticas de estado em relação ao desenvolvimento econômico e social às quais o PNLN está ligado. O foco da pesquisa não é avaliar o programa ou criticar suas políticas e estruturas, mas compreendê-los, o que significa dizer: compreender as práticas sociais, as formações discursivas e os interesses ideológicos nos quais o ensino e a aprendizagem do PNLN estão embutidos. O capítulo se divide em três seções. A primeira introduz a base teórica da pesquisa; a segunda discute o papel do PNLN como parte da política governamental de reconciliação racial/étnica e desenvolvimento. Aqui a autora diz, considerando excertos de pronunciamentos das autoridades da Namíbia: "o letramento é primariamente concebido em termos de desenvolvimento de recursos humanos para a economia" (p. 46). A seção conclusiva descreve algumas das práticas de letramento nas aulas do PNLN. O conhecimento visto, por exemplo, como competição pela Nova Ordem Epistemológica justifica decisões e escolhas dentro do programa. Papen argumenta que a concepção dominante de letramento e educação e os amplos alvos políticos se fixaram ao letramento, não só no conteúdo do programa, mas também privilegiaram certas compreensões de conhecimento e influenciaram os tipos de práticas de letramento do PNLN.

Encerram a primeira parte do livro o Capítulo 3, "More than just chanting: multilingual literacies, ideology and teaching methodologies in rural Eritrea", de M. W. Wright; e o Capítulo 4, "Betrayal and solidarity in ethnography on literacy: revisiting research homework in a north Indian village", de P. Chopra. Além das valiosas descrições da pesquisa, apresentam, por meio da prática, importantes pressupostos a serem seguidos na etnografia. Respectivamente, registram a necessidade da suspensão de julgamento a priori em relação às metodologias de ensino aplicadas para focalizar as metodologias que estão sendo utilizadas para compreendê-las. E discutem o envolvimento crítico e autoconsciente que o(a) pesquisador(a) precisa ter na relação entre o que ela chama de 'traição' e 'solidariedade'. O texto de Chopra cumpre também o papel de repensar dilemas que atravessam todos os outros capítulos; uma amostra é a afirmativa da autora: 
A ação de compreender as pessoas, como sujeitos de letramento, buscando representar suas práticas, como construção do nosso olhar, para mim envolve um contínuo processo de releitura. Reler para tornar-me consciente das lacunas e ausências ocultas em minha leitura como um ato de 'conhecer' as práticas de outras pessoas (p. 87).

Na segunda parte da obra, intitulada "Literacy and development: local literacies and development agendas", os autores apresentam uma abordagem sensível aos significados locais do processo de desenvolvimento em geral e de letramento em particular. É apresentada uma série de pesquisas sobre o letramento em alguns domínios de prática: a propriedade de terra e o desenvolvimento econômico, a língua do letramento em contexto multilíngüe, a esfera comercial, a saúde, o controle do Estado sobre as pessoas e o letramento relacionado a políticas de gênero. São os Capítulos: 5, "Literacies, languages and developments in Peruvian Amazonia", de S. Aikman; 6, "Another language, another literacy? Practices in northern Ghana", de P. Herbert and C. Robinson; 7, "Literacy and the market: the economic uses of literacy among the peasantry in north-west Bangladesh", de B. Maddox; 8, "Women's literacy and health: can an ethnographic researcher find the links?", de A. Robinson-Pant; 9, "Household literacy environments as contexts for development in rural China", de R. Stites; e 10, "Literacies, gender and power in rural Pakistan", de S. Zubair.

Entre esses capítulos destacam-se o 7 e o 10. Maddox realizou sua pesquisa no noroeste de Bangladesh, na pequena cidade de Nilphamary e em seus arredores, onde a principal atividade econômica é agrícola e os camponeses são considerados iletrados. Além disso, "pobreza e iletramento são comumente tratados como termos sinônimos" (p. 137). O autor dá atenção especial para as relações de letramento que se desenvolvem no comércio local, explanando, entre outras questões, sobre vínculos empregatícios; os papéis dos homens e das mulheres; questões de identidade; a associação da língua árabe à religião e da língua bangla à economia. Em sintonia com a concepção de Fairclough (2003: 75) de que "gêneros como formas de interação constituem tipos particulares de relações sociais entre pessoas que interagem", o autor descreve alguns gêneros e suas relações com os eventos específicos. Uma consideração relevante do trabalho de Maddox é a percepção de que o letramento econômico é uma fusão de "literacy" e "numeracy" na prática, o que pode ser observado, por exemplo, no mercado de peixes. É na esteira dessa análise e de outras que o autor argumenta que um ensino baseado nessa prática proveria uma aprendizagem significativa que serviria de base para outras. 
Zubair, no Capítulo 10, trata da difícil realidade educacional do Paquistão e registra as práticas de letramento relacionadas a dois povoados vizinhos na área da língua seraiki do Punjab Meridional. Seus relatos sobre a condição da mulher naquela comunidade têm semelhança em alguns aspectos com o grupo pesquisado por Magalhães (1995: 201) e na observação dessa pesquisadora de que "tais mulheres, sem acesso à leitura e à escrita, são duplamente vítimas numa sociedade androcêntrica e grafocêntrica". Os achados de Zubair na pesquisa podem contribuir com as políticas de desenvolvimento, conhecendo como a leitura e a escrita produzem sentido na vida das mulheres e como poder e identidade são contestados, desafiados e negociados discursivamente nas práticas de letramento. Um exemplo é a observação de que enquanto os homens consideram o letramento funcional suficiente, a preocupação das mulheres com o letramento tem relação com a reflexão sobre letramento como alvo. No decurso da pesquisa, ela questionou a relação dinâmica de poder que atravessava sua identidade de pesquisadora e procurou dar voz ao outro como também compartilhar o conhecimento com os participantes.

A. Rogers assina o posfácio: "Afterword: problematising literacy and development", no qual cumpre o objetivo a que se propõe no título e destaca o fato de os programas de desenvolvimento se mostrarem altamente problemáticos como um dos resultados mais importantes apresentados nos ensaios.

Literacy and development apresenta um grande avanço em pesquisas etnográficas relativas ao letramento e à própria metodologia em suas reflexões sobre pesquisador(a), pesquisado(a), sujeito, participação, "empowerment" etc. Apesar de Street ter citado o trabalho de Kress e van Leeuwen (1996), ficaram lacunas nas pesquisas sobre o aspecto visual no letramento (mínimas menções, como por exemplo, no estudo da Namíbia). Não obstante, a obra é valiosa, dentre outras razões, por apresentar aspectos multiculturais de diferentes lugares do mundo e, com certeza, é indicada para educadores, estudiosos do letramento e principalmente para as pessoas envolvidas em desenvolvimento e políticas de letramento. 


\section{REFERÊNCIAS BIBLIOGRÁFICAS}

Barton, D. \& Hamilton, M. (Orgs.) Local literacies. Reading and writing in one community. Londres e Nova York: Routledge, 1998.

Barton, D., Hamilton, M. \& Ivani, R. (Orgs.) Situated literacies. Reading and writing in context. Londres e Nova York: Routledge, 1999.

Bourdieu, P. e Passeron, J.-C. Reproduction in society, education and culture. Londres: Sage, 1977.

Fairclough, N. Analysing discourse. Londres e Nova York: Routledge, 2003.

Ivanic, U. R. Writing and identity. Amsterdã e Filadélfia: John Benjamins, 1997.

Kress, G \& van Leeuwen, T. Reading images. The grammar of visual design. Londres: Routledge, 1996.

Magalhães, I. Práticas discursivas de letramento: a construção da identidade em relatos de mulheres. In: Kleiman A. (Org.) Os significados do letramento. Uma nova perspectiva sobre a prática social da escrita. Campinas: Mercado de Letras, 1995, pp. 201-35.

Martin-Jones, M. \& Jones, K. (Orgs.) Multilingual literacies. Reading and writing different worlds. Amsterdã e Filadélfia: John Benjamins, 2000.

Street, B. Social literacies. Londres e Nova York: Longman, 1995.

.Literacy events and literacy practices. Theory and practice in the "New Literacy Studies". In: Martin-Jones M. \& Jones K. (Orgs.) Multilingual literacies. Reading and writing different worlds. Amsterdã e Filadélfia: John Benjamins, 2000, pp. 17-29.

DécioBessa-deciobessa@yahoo.com.br 